\title{
ForcaBRAS - Um Jogo Educativo para o Aprendizado Básico de LIBRAS
}

\author{
Lenington C. Rios ${ }^{1}$, Washington P. Batista ${ }^{1}$, Claudia P. Pereira ${ }^{2}$, Victor T. Sarinho \\ ${ }^{1}$ Laboratório de Entretenimento Digital Aplicado (LEnDA) \\ UEFS - Feira de Santana - Bahia - Brasil \\ ${ }^{2}$ Departamento de Exatas (DEXA) \\ UEFS - Feira de Santana - Bahia - Brasil \\ \{lenitorios, wstroks\}@gmail.com, \{claudiap, vsarinho\}@uefs.br
}

\begin{abstract}
The Brazilian Sign Language (LIBRAS) is a communication resource that provides the social insertion of people with hearing impairment. This article presents ForcaBRAS, a proposal of free educational game for the playful and intuitive teaching of the alphabet and numerals representation using LIBRAS. For this, motivations, game logic and technological resources used for the development of the application are presented. It concludes with the verification and the validation of the game for a young and adult audience and presentation of future development and large-scale use proposals for the game.
\end{abstract}

Resumo. A Língua Brasileira de Sinais (LIBRAS) é um recurso de comunicação que proporciona a inserção social de pessoas com deficiência auditiva. Este artigo apresenta o ForcaBRAS, uma proposta de jogo educativo gratuito para o ensino lúdico e intuitivo da representação do alfabeto e de numerais usando LIBRAS. Para tal, são apresentados motivações, lógica de jogo e recursos tecnológicos utilizados para o desenvolvimento da aplicação. Conclui-se com a verificação e a validação do jogo para um público jovem e adulto e propostas futuras para o aperfeiçoamento e a utilização em larga escala do mesmo.

\section{Introdução}

Línguas baseadas em sinais são de extrema importância para a inclusão social de deficientes auditivos em geral. Trata-se de um recurso de comunicação que apresenta uma estrutura gramatical própria, além de aspectos semânticos, morfológicos, entre outros da própria linguagem em si, tais como o uso de gestos e de combinações com expressões faciais e corporais para a sua comunicação [Dessen and Brito 1997].

A Língua Brasileira de Sinais (LIBRAS), que é a primeira língua oficial dos surdos brasileiros, é considerada a segunda língua oficial do país [Brasil. Lei n. 10.436 2002]. Trata-se de "uma língua de modalidade gestual-visual porque utiliza, como canal ou meio de comunicação, movimentos gestuais e expressões faciais que são percebidos pela visão" [FENEIS 1999/2002].

Atualmente, LIBRAS é um componente curricular obrigatório nos cursos de licenciatura e de fonoaudiólogos, e opcional para outros cursos de nível superior [Rossi 2015]. Entretanto, LIBRAS ainda é pouco difundida nas escolas e na sociedade como um todo, o que gera uma enorme dificuldade na comunicação entre deficientes auditivos e 
VII Congresso Brasileiro de Informática na Educação (CBIE 2018)

Anais do XXIX Simpósio Brasileiro de Informática na Educação (SBIE 2018)

a população em geral. Neste sentido, este artigo apresenta o ForcaBRAS, um jogo educativo que objetiva auxiliar o ensino e a aprendizagem do alfabeto e numerais em LIBRAS para crianças em geral.

\section{Metodologia}

Diferentes jogos digitais foram desenvolvidos nos últimos anos com foco em LIBRAS, a exemplo do LibrasZap que define um jogo de mensagens instantâneas para a avaliação de conhecimento de palavras em LIBRAS [Sarinho 2017]. No caso do ForcaBRAS, este aplica regras, elementos e dinâmicas do jogo de forca (Hangman). A ideia do jogo consiste em selecionar representações em LIBRAS de caracteres do alfabeto, as quais são avaliadas pelo jogo informando se a mesma faz parte ou não da palavra a ser decifrada. ForcaBRAS também possui uma versão para trabalhar com as quatro operações básicas da matemática (soma, subtração, multiplicação e divisão), exibindo um teclado numérico e uma operação matemática onde o jogador deve informar o resultado correto da mesma.

Para a etapa de construção do jogo, elaborou-se o design das interfaces e a implementação do jogo para uma versão desktop. Sua codificação se deu através do ambiente Godot (Figura 1), um motor de jogo open source que permite o desenvolvimento rápido de interfaces complexas de uma maneira compartilhada com designers e animadores [Linietsky et al. 2014].

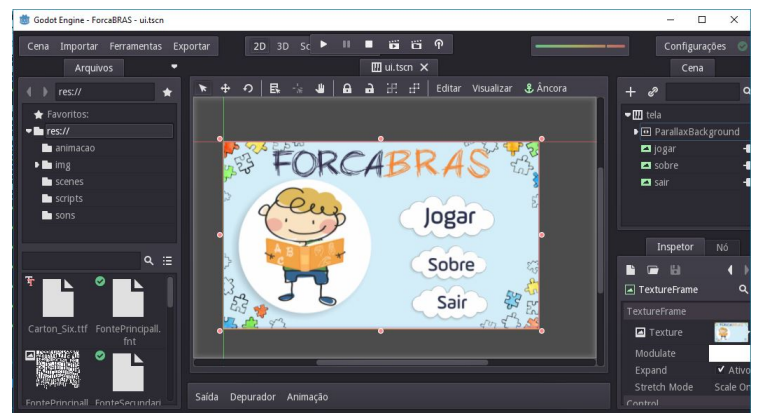

Figura 1. Ambiente de produção Godot do jogo ForcaBRAS.

Para a verificação e validação do ForcaBRAS, efetuou-se a aplicação do jogo em sala de aula com estudantes do ensino fundamental de uma escola pública (Figura 2), bem como a disponibilização do mesmo para estudantes de cursos de graduação convidados por intermédio de redes sociais a participarem do processo de avaliação do jogo. Como instrumentos de coleta de informações sobre o seu uso, foram aplicados questionários para avaliação do nível de aprendizagem em LIBRAS proporcionado pelo jogo, e diário de bordo para sistematização, reflexão e detecção de nuances de experimentação com o jogo. Os questionários foram aplicados para dois públicos, infanto juvenil e adulto, que não apresentavam deficiência auditiva, com a intenção de verificar a efetividade da aprendizagem de LIBRAS. Já o diário de bordo, escrito após a aula pela professora responsável pela turma de ensino fundamental, descreve as reações dos seus respectivos estudantes enquanto interagiam com o jogo, tais como dificuldades, dúvidas e elogios identificados.

\section{Resultados e Discussões}

Com relação ao jogo final produzido, este apresenta dois níveis de dificuldades: normal e difícil. No nível normal, tanto o alfabeto quanto os numerais em LIBRAS são apresenta- 
VII Congresso Brasileiro de Informática na Educação (CBIE 2018)

Anais do XXIX Simpósio Brasileiro de Informática na Educação (SBIE 2018)
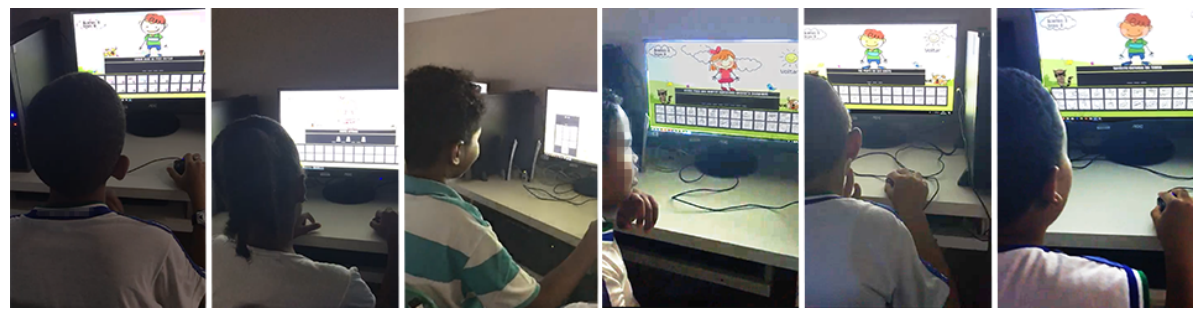

Figura 2. Aplicação do jogo ForcaBRAS com estudantes do ensino fundamental de uma escola pública.

dos juntamente com seu caractere. Já no nível difícil, são exibidos apenas os gestos em LIBRAS posicionados de forma aleatória. Ao iniciar o jogo, o jogador deve escolher um personagem (Figura 3a). Cada fase do jogo é composta por: uma palavra e sua dica, para o modo Alfabeto (Figura 3b); ou uma operação básica de matemática e o seu resultado, para o modo Numeral (Figura 3d). Ao completar a resposta, o jogador avança para a próxima fase e, cada vez que o jogador erra, uma parte do corpo do personagem desaparece. Caso o jogador tenha perdido todas as partes do corpo do personagem (totalizando sete), o resultado será exibido na tela e o jogador será questionado se deseja continuar jogando, além de ser exibido a mensagem "perdeu". Quando o usuário acerta uma pergunta, é exibida na tela uma mensagem de "parabéns" (Figura 3c).

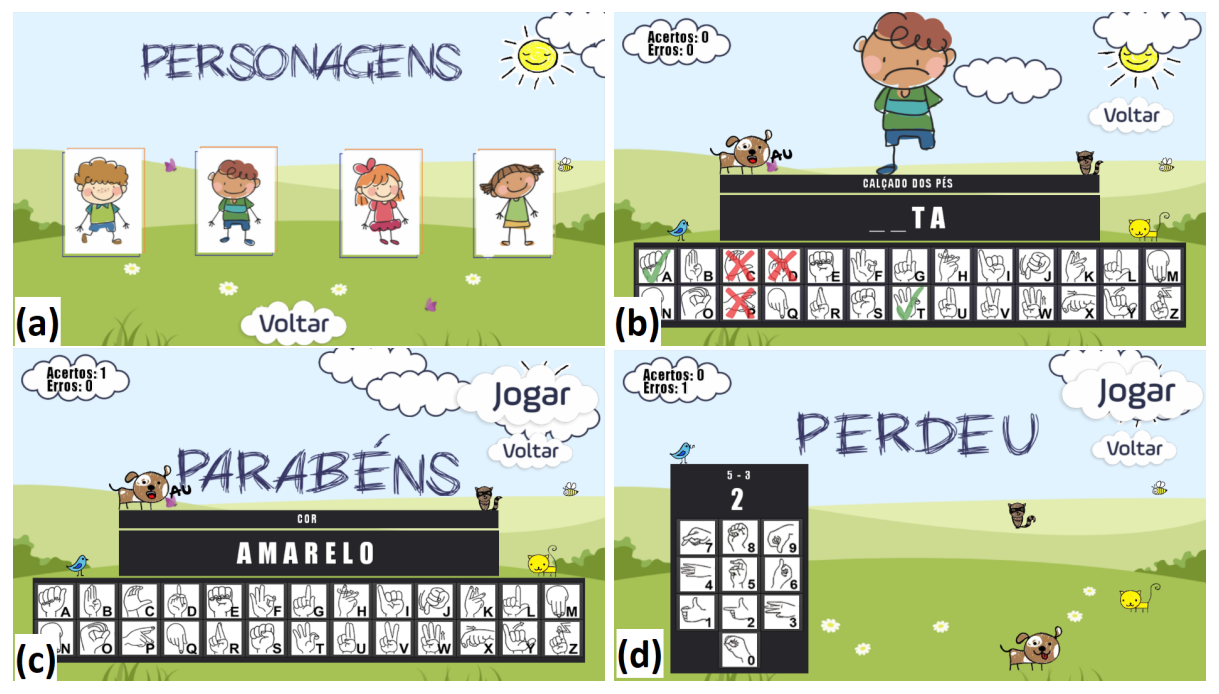

Figura 3. (a) Personagens selecionáveis, (b) Modo Alfabeto, (c) Condição final do jogo em caso de acerto, (d) Modo Numeral, e condição final do jogo em erro.

Com relação a avaliação de usabilidade do jogo ForcaBRAS Mobile, foi aplicado um questionário, com respostas em uma escala de 1 a 5 , que são representadas por discordo e concordo. O questionário contou com a participação de 41 pessoas, as quais foram convidadas através de redes sociais. Uma das questões levantadas pelo questionário buscava, por exemplo, avaliar o quanto de motivação em jogar o jogo foi gerado pelas fases Alfabeto e Numeral. Como resultado, é possível confirmar a avaliação positiva do jogo em si com médias das respostas obtidas maiores do que 4, conforme Figura 4.

Com relação as outras respostas obtidas nas demais questões avaliadas (Figura 5), tem-se que o jogo ForcaBRAS Mobile, além de proporcionar a aprendizagem de LIBRAS 
VII Congresso Brasileiro de Informática na Educação (CBIE 2018)

Anais do XXIX Simpósio Brasileiro de Informática na Educação (SBIE 2018)

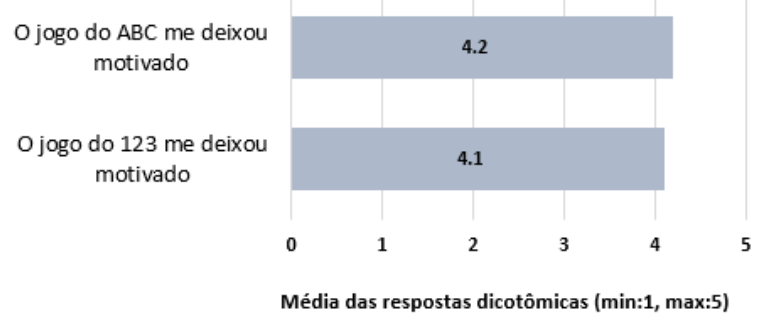

Figura 4. Avaliação da motivação obtida pelo jogo ForcaBras Mobile.

de uma maneira divertida, também apresentou uma jogabilidade fácil, bem como uma interface agradável para os jogadores. Estratégias como o embaralhamento de letras e números, a apresentação de dicas durante as partidas, e a própria motivação em aprender gerada pelo uso do jogo em si também foram bem avaliadas pelos jogadores.

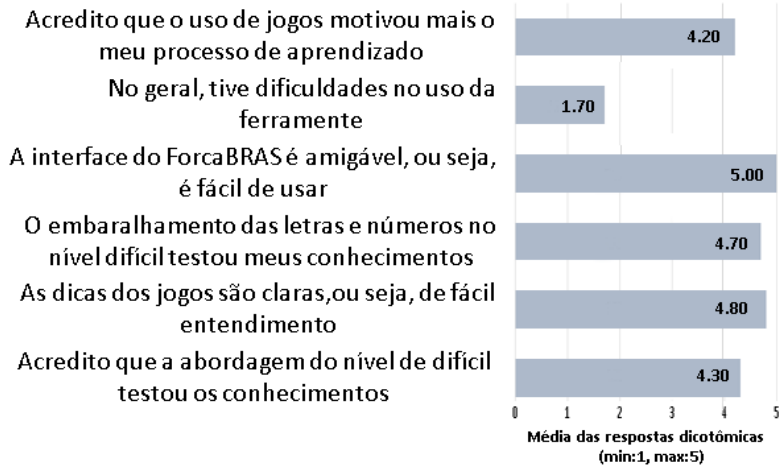

Figura 5. Questões de avaliação de usabilidade do jogo ForcaBras Mobile.

Finalmente, com relação ao diário de bordo produzido durante a aplicação do jogo na turma de ensino fundamental da escola municipal, registrou-se os seguintes tópicos:

- Metodologia de ensino aprendizagem: Percebe-se que a metodologia de ensino é fundamental para o entendimento e a manutenção do interesse do aluno em determinado tema. Com isso, foi relatado pela professora que já tinham sido aplicadas metodologias lúdicas no ensino de Português e Matemática, permitindo ao aluno uma maior autonomia no processo de aprendizado, e, com o jogo, foi possível complementar as informações já ditas em sala de aula, além é claro do aprendizado dos sinais da LIBRAS.

- Alunos: A aplicação do jogo ForcaBRAS contou com a participação de 13 alunos, sendo eles divididos em dois grupos, devido a disponibilidade de poucas máquinas no laboratório da escola.

- ForcaBRAS: O jogo e suas fases foram apresentados e explicados aos estudantes antes do seu uso, orientando-os a iniciar pela fase normal e, em seguida, partir para a difícil. Em primeira instância, boa parte dos estudantes não tiveram complicações, apenas um participante que já apresentava dificuldade na grafia de palavras, o que reforça que a aplicação permite o desenvolvimento das habilidades e dos conhecimentos de Português e Matemática. Para a fase difícil, o jogo apresentou desafio para os estudantes que não tinham conhecimento prévio na LIBRAS, que com o tempo foram se aperfeiçoando nesta língua. 
VII Congresso Brasileiro de Informática na Educação (CBIE 2018)

Anais do XXIX Simpósio Brasileiro de Informática na Educação (SBIE 2018)

- Motivações: No universo interdisciplinar, o jogo faz jus ao seu propósito de ensinar LIBRAS trazendo também áreas do conhecimento, como Matemática e Português. Ao término da aplicação, os estudantes continuavam a trocar experiências vivenciadas nele e permaneciam interessados em jogá-lo novamente.

- Sugestões: Foi sugerida a implementação de escolha das operações matemáticas, ou seja, dividir as operações e deixar a opção de escolha para o jogador. Outra sugestão proposta foi a abordagem de outras áreas de conhecimento para o jogador.

\section{Conclusões e Trabalhos Futuros}

Este artigo apresentou ForcaBRAS, um jogo educativo que busca facilitar processo de ensino e aprendizagem, de forma lúdica e intuitiva, de alfabeto/numerais em LIBRAS [Batista et al. 2017], além de, em paralelo, reforçar assuntos trabalhados em sala de aula, como formação de palavras e operações matemáticas. ForcaBRAS também pode ser apresentado como uma forma de conscientização didática e gratuita da importância de se aprender LIBRAS, representando um passo relevante na busca da ressocialização da crescente população de deficientes auditivos do país.

Como trabalhos futuros, tem-se a construção de novos jogos para o ensino e o aprendizado da LIBRAS, bem como a aplicação de novos recursos tecnológicos atualmente disponíveis, tais como computação visual e realidade virtual/aumentada. Também se pretende criar uma interação multiplayer para o ForcaBRAS, na qual os jogadores poderão competir uns contra os outros em qualquer ente da federação, compartilhamento de resultados em redes sociais e ranking de melhores pontuações para fins de divulgação do mesmo. Além disso, pretende-se realizar experimentos mais formais de modo a obter sugestões pedagógicas para a aplicação.

\section{Referências}

Batista, W. P., Rios, L. d. C., and Sarinho, V. T. (2017). Forcabras - aplicando a computação visual no aprendizado do alfabeto de libras. In: Workshop de eXperimentos em Tecnologia Bahia-Alagoas-Sergipe, 2017, Cruz das Almas. ERBASE - Escola Regional de Computação Bahia-Alagoas-Sergipe.

Brasil. Lei n. 10.436, d. . d. a. d. . (2002). Dispõe sobre a língua brasileira de sinais-libras e dá outras providências.

Dessen, M. A. and Brito, A. M. W. d. (1997). Reflexões sobre a deficiência auditiva e o atendimento institucional de crianças no brasil. Paidéia (Ribeirão Preto), (12-13):111134.

FENEIS. (1999/2002). Revista da feneis. números 1 ao 13. (2-16).

Linietsky, J., Manzur, A., and Community, G. (2014). Godot docs. http://docs.godotengine.org/. Accessed: 2018-06-01.

Rossi, R. A. (2015). A libras como disciplina no ensino superior. Revista de Educação, 13(15).

Sarinho, V. T. (2017). Libraszap-an instant messaging game for knowledge assessment in brazilian sign language. Brazilian Journal of Computers in Education, 25(01):44. 